\title{
STUDIES ON THE SYSTEMATICS OF THE BEROTHIDAE, \\ PART I: A REDESCRIPTION OF \\ THE GENUS SPHAEROBEROTHA NÁVAS, WITH A CRITIQUE OF \\ THE TAXONOMIC CHARACTERS \\ USED IN THE BEROTHINAE (NEUROPTERA)
}

\author{
By Ellis G. MacLeOD ${ }^{1}$ \\ INTRODUCTION
}

As a by-product of the recent review by P. A. Adams and myself (MacLeod and Adams, 1967) of the subfamily classification of the Berothidae, new information has been uncovered concerning the identity and taxonomic status of some of the more poorly known members of this family. Because of the general difficulty in securing type specimens for study and because of the great paucity of these insects in most collections, I do not consider it advisable to undertake, at this time, the full, species-level revision which this family so badly needs. Nevertheless, sufficient data are now at hand to encourage the view that a long-term, piecemeal study of the more disorderly sections of the family may ultimately produce a better taxonomic understanding of these insects.

Accordingly, the present series of publications has been initiated for the purpose of providing a vehicle for the redescription of key genera and species, for the discussion of the taxonomic utility of various systematic characters, for the reevaluation of the validity and systematic position of the numerous genera of the Berothinae, and for the publication of such ecological and morphological information as provides insight into the adaptive basis of certain evolutionary specializations. If successful, this approach should eventually produce at least a partial, generic-level revision of the family and should lay a better foundation for a future, thoroughgoing revision of the species than exists at the present time.

The first paper of this series will be devoted to a redescription of the poorly known genus Sphaeroberotha Navás and to a preliminary discussion of the relationships of certain genera of the Berothinae. In the course of this discussion I have set forth my views concerning the usefulness of certain of the generic-level taxonomic characters

\footnotetext{
${ }^{1}$ Department of Entomology, University of Illinois, Urbana, Illinois.
}

Manuscript received by the editor December 2, 1967 
which have been used in the past and have noted which additional characters I feel should be carefully evaluated in future descriptive and taxonomic work with this family.

\section{The Genus Sphaeroberotha}

Navás based his description of the type species of Sphaeroberotha, $S$. dumonti, on a single female. Although he included the species Costachella geyri (Esben-Petersen) in his new genus as a second species, his characterization of Sphaeroberotha was, in fact, based almost solely on $S$. dumonti since he had only a drawing, whose accuracy he questioned, of the wings of Esben-Petersen's species for study. Through the great kindness of Dr. S. Kelner-Pillault of the Muséum National d'Histoire Naturelle, Paris, I have been permitted to borrow and study the holotype of $S$. dumonti from which the following redescriptions and discussions are drawn.

\section{Sphaeroberotha Navás}

Sphaeroberotha Navás, 1930, Broteria 26: 133-134. Type species (by original designation): Sphaeroberotha dumonti Navás, 1930. Tjeder, 1958, South African Animal Life 6: 281-282. MacLeod and Adams, 1967, Psyche 74: 254, 256, 258.

Description. A genus belonging to the Berothinae. Face short, extending only slightly ventrad of eyes; vertex a slightly raised triangular area, with two weak lateral tubercles at its posterolateral corners; postgenae moderately inflated. Scape only slightly elongate; antennomeres distal to scape subspherical, each with two rings of distally directed setae which extend as far as the next antennomere; distal antennomere more elongate, acuminate. Mouthparts well developed, mandibles with tips crossing when jaws are closed. Pronotum moderately robust, slightly wider than long, with two transverse furrows, strongly deflexed laterally. Fore legs lacking raptorial modifications.

Wings (Fig. I) elongate, with rounded tips, lacking any indication of falcation; Sc connected distally to $R_{1}$ by an oblique cross vein at edge of pterostigma; two radial cross veins; free basal piece of MA (Fig. I, b) oblique, slightly proximal to basal fork of MP; a weak series of outer gradate crossveins present. Fore wing: probable vestige of recurrent humeral vein present basally in costal cell as a steeply inclined crossvein with a distal fork; stems of $M$ and $R$ fusing just proximal to basal subcostal crossvein; outer gradate crossvein between the branches of MP generally in line with gradates above and below this vein, not far proximal to these; jugal vein and 
lobe absent; with weakly developed lines of flexion present between $\mathrm{MA}$ and $\mathrm{MP}$ and between $\mathrm{CuP}$ and $\mathrm{IA}$; crossveins and forkings lacking dense tufts of erect setae; similar dense tufts from trichosors of wing margin also lacking. Hind wing: with $\mathrm{C}$ and $\mathrm{Sc}$ running very closely together for most of distance from wing base to pterostigma; no basal crossvein in subcostal space; stem of $M$ passing beneath $\mathrm{R}$, but free from this vein to base of wing; $\mathrm{CuA}$ paralleling posterior margin and reaching into distal I/3 of wing, with numerous pectinate marginal forks; no trace of $\mathrm{CuP}$ present; jugal vein absent; a weak line of flexion developed between bases of $M$ and $\mathrm{R}$, continuing a short distance distal to the basal free piece of MA.

Male unknown. Female (Figs. 2, 3, 4) : 7th sternite (Figs. 2, $3,7 \mathrm{~S}$ ) widely unsclerotized posteriorly and in midline, represented as two separated bilateral pieces, without the development of thin, rod-like lateral sclerites; 8th sternite (Figs. 2, 3, 8S) thin and straplike laterally, with an anteriorly directed median lobe; 8th gonocoxites (Figs. 2, 3, 8gcx) represented as a small concave sclerite just anterior to gonopore; 9th gonocoxites (Figs. 2, 3, 9gcx) large, with well-developed, elongate hypocaudae; 9th gonapophyses lacking; Ioth sternite (Fig. 3, IOS) represented as a weakly sclerotized area dorsad of 9th gonocoxites; genital chamber (Fig. 2. gen. ch.) large, with duct from collaterial gland emptying into it posteriorly, widely confluent with copulatory bursa (Figs. 2, 3, 4, cop. b.), closed by anteriad appression of membranous area between 9th gonocoxites against large convex lobe of weakly sclerotized cuticle just posteriad of 8th sternite; copulatory bursa somewhat small, consisting of membranous distal portion and a well-sclerotized, coiled proximal area from which the spermathecal duct originates; spermathecal duct (Fig. 4, sp. d.) elongate and looped; spermatheca (Figs. 2, 4, sp.) intricately coiled, sclerotized, with a prominent spherical diverticulum and with apparent cuticular attachments for glandular epithelium along one side just proximal to origin of fertilization canal; fertilization canal lacking usual fringe of cuticular attachments for glandular epithelium (Fig. 4, fert. c.).

Type species: Sphaeroberotha dumonti Navás.

\section{Sphaeroberotha dumonti Navás}

Sphaeroberotha dumonti Navás, 1930. Broteria 26: 134-135, fig. 44. Described from a single female now located in the collections of the Muséum National d'Histoire Naturelle, Paris, MacLeod and Adams, 1967, Psyche 74: 254. 
Description. Face and vertex dark yellow, with stout white setae of moderate length and with a suggestion of dark spotting about the bases of the vertex setae; labrum with a transverse row of thinner, more-elongate setae. Scape short, twice as long as broad, setae like those of vertex but darker, right antenna with fifty-six antennomeres distal to scape, each with a thin brown ring, setae of a dark amber color. Thorax tannish brown (probably much discolored), with no indications of any original mottling of color pattern. Prothoracic legs pale yellow, femora and tibiae with a few scattered darker spots.

Wings (Fig. I) with anterior margin of fore wing slightly concave; no maculations on membrane, but with longitudinal veins of fore wing with dark dots at setal bases; outer gradate series with 4 crossveins in the anterior wing, 3 crossveins in the posterior wing; fore wing length $6.7 \mathrm{~mm}$.

Thorax and wing margin with sparse elongate white setae (probably mostly rubbed off), posterior wing margins with more-elongate, silky pale yellow setae; setae on wing veins white, shorter than those on body, directed basally at about a $45^{\circ}$ angle to longitudinal axis of vein, length about equal to average distance between veins; no evidence of squamae on body, legs, or wings.

Abdominal structures as in Figs. 2-4: 8th sternite with short setae and with an apodeme reenforcing the strap-like lateral arms, anteriorly directed median lobe slightly pedunculate in lateral view, somewhat spatulate in shape when viewed ventrally; cuticle between 8th sternite and 8th gonocoxites a weakly sclerotized convex lobe; 9th gonocoxites somewhat triangular in lateral aspect, with a distinct posterior lobe. Sclerotized, proximal portion of bursa wound in a snail-like coil of decreasing diameter, from the tip of which the spermathecal duct originates; spermatheca with coiling pattern as in Fig. 4.

The pinned type is missing its left antenna distal to the scape, right fore leg distal to the femur, mesothoracic legs distal to their coxae, metathoracic legs distal to the coxa (right) and femur (left) and most of the left hind wing. The abdomen has been removed, cleared, and placed in glycerine in a microvial on the pin with the specimen. The holotype was collected at a light in May, I927 by C. Dumont at Nefta, Tunisia.

\section{Discussion}

Such specialized features as the large, anteriorly directed 8th sternum, well-developed hypocaudae, manner of closure of the genital 

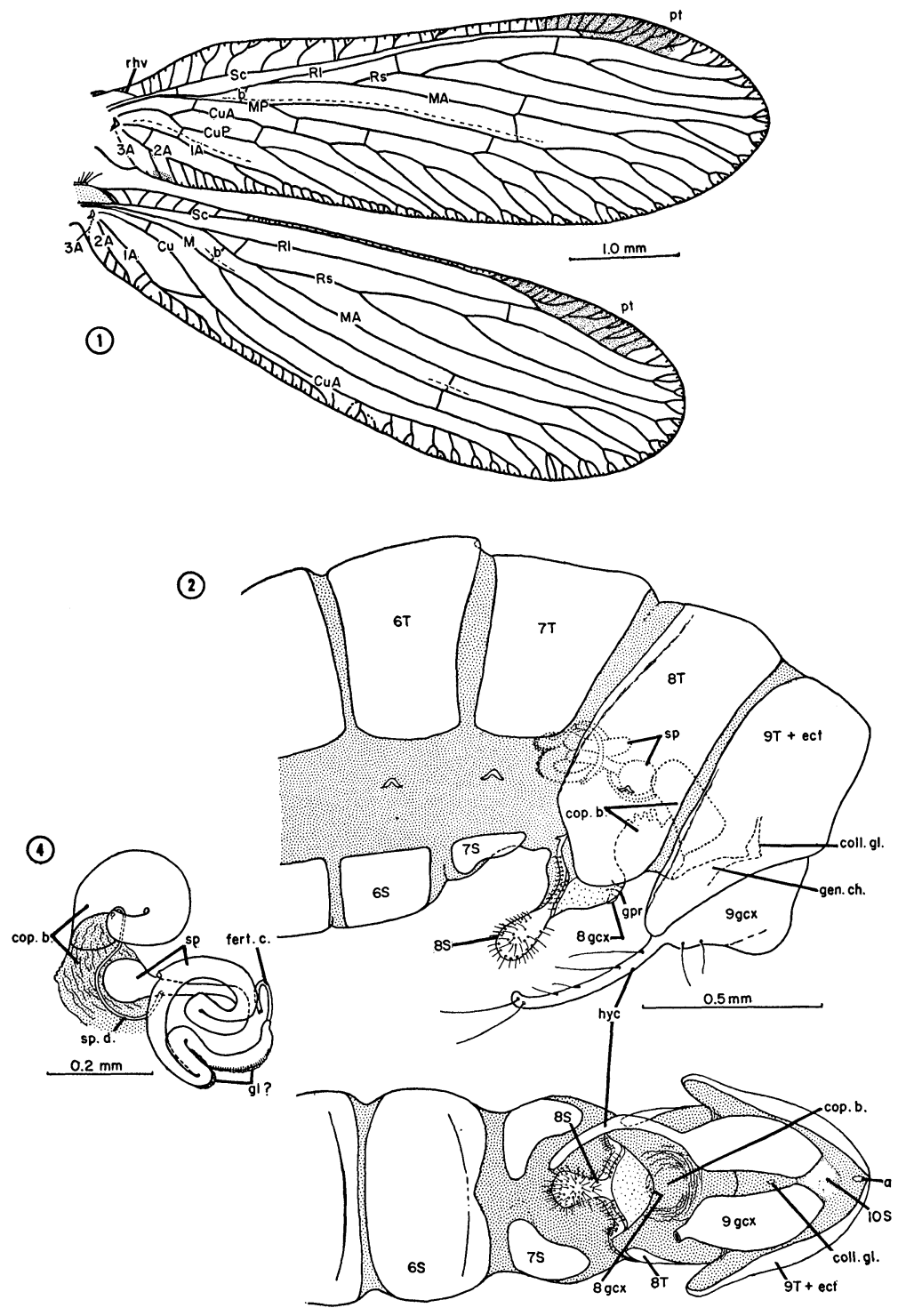

(3)

MacLeod - Berothids 
chamber, and elongate wings show that Sphaeroberotha quite properly belongs to the Berothinae. Within this group, however, its systematic position is far from clear. Indeed, because of the poor state of our knowledge concerning many other genera of the Berothinae, it is not even certain that $S$ phaeroberotha represents a valid genus.

Along with the berothines Protobiella Tillyard, Spermophorella Tillyard, Nodalla Navás, Costachillea Navás, and Cycloberotha Navás, Sphaeroberotha shares the feature of a rounded outer wing margin. However, as the members of the other three subfamilies of the Berothidae share this same characteristic, by itself such a similarity shows nothing about the relationships of these genera of the Berothinae. These six genera do, however, possess certain other similarities and, as they have, to varying degrees, been treated as a unit in previous taxonomic works, they will be considered together here.

Prior to his description of Sphaeroberotha, Navás himself (1929) separated the first three of these genera ${ }^{2}$ from the other two by the presence of a fusion between $S c$ and $R_{1}$ in the region of the pterostigma which was presumed to be lacking in Costachillea and $C y$ cloberotha (and in the subsequently described Sphaeroberotha) where

EXPLANATION OF PLATE 37

Drawn from the female holotype of Sphaeroberotha dumonti Navás in the Muséum National d'Histoire Naturelle, Paris. All from camera lucida tracings. Fig. 1. Right fore- and hindwing. Figs. 2 and 3. Lateral and ventral aspects of the tip of the abdomen. (Setae indicated only on 8th-sternite, 9th gonocoxites, and hypocaudae. Right hypocauda omitted from Fig. 3.) Fig. 4. Copulatory bursa and spermatheca, dorsal aspect with posterior end directed toward top of page.

Abbreviations: a-anus; 1A, 2A, 3A-1st, 2nd, 3rd anal veins; $\mathrm{b}$ - basal free piece of anterior median vein; coll. gl. - collaterial gland duct and opening; cop. b. - copulatory bursa; $\mathrm{Cu}$ - base of cubital vein; $\mathrm{CuA}$ - anterior cubitus; $\mathrm{CuP}$ - posterior cubitus; fert. c. - fertilization canal; 8 gcx, 9 gcx-8th, 9th gonocoxites; gen. ch. - genital chamber; gl? - possible cuticular canals from spermathecal gland cells; gpr-gonopore; hyc - hypocauda; $\mathbf{M}$ - base of median vein; $M A$ - anterior median vein; $\mathrm{MP}$ - posterior median vein; pt-pterostigma; R1 - first branch of radial vein; Rs - radial sector; rhv - vestige of recurrent humeral vein; $6 \mathrm{~S}, 7 \mathrm{~S}, 8 \mathrm{~S}, 10 \mathrm{~S}-6 \mathrm{th}, 7 \mathrm{th}, 8 \mathrm{th}, 10$ th sternites; Sc-subcostal vein; sp - spermatheca; sp.d. - spermathecal duct; 6T, 7T, 8T-6th, 7th, 8th tergites; $9 \mathrm{~T}+$ ect - fused 9th tergite and ectoproct.

\footnotetext{
${ }^{2}$ Navás further separated these three genera by placing Protobiella and Spermophorella in one tribe, the Spermophorellini, and Nodalla in a second tribe, the Nodallini. No diagnostic features by which these two tribes might differ are apparent from his descriptions; indeed the Spermophorellini are not even included in his key to tribes (pp. 17-18) in his revision of 1929!
} 
these veins are united by a short crossvein. This opposing set of characters has been much used in the supraspecific taxonomy of the Berothidae, although there are several complicating features of this area of the wing which undermine the usefulness of this set as a taxonomic character.

For example, there are many cases in which the approach of Sc and $R_{1}$ is so close that the decision as to whether these veins are actually fused or not becomes arbitrary. A more subtle source of confusion arises from variations in the degree of obliquity of the crossvein, so that in some cases an apparent fusion of $S c$ and $R_{1}$ occurs when in reality these veins are quite separate. The ease with which this condition can mimic a fusion of these veins is further compounded by the fact that the true termination of Sc is often masked in the thickening and pigmentation of the adjacent pterostigma. In addition to these complexities, this set of taxonomic characters is also often subjected to a high degree of individual variability. I feel, therefore, that the degree of fusion of these veins is of a limited utility and that the use of this feature at the tribal level can probably not be justified. On this basis, then, the genera Protobiella, Spermophorella, and Nodalla cannot be excluded from consideration in ascertaining the relationships of Sphaeroberotha.

Costachillea has been considered to differ from Sphaeroberotha and Cycloberotha by the presence of an "internal radial vein" (i.e. the vein labeled b in Fig. I of the present paper) in these latter two genera, which is presumed to be lacking in Costachillea. ${ }^{3}$ Here again

\footnotetext{
${ }^{3}$ Because of the rather far distal position of the basal piece of MA in many berothids, it might be considered that this vein is a true crossvein, the real basal piece having been lost with the close approximation of the stems of $R$ and $M$. This possibility seems to be strengthened by the fact that in the fore wings of several genera (Trichoberotha and some species of Lomamyia show this especially well) there does seem to be an additional, more proximal vein between the nearly adjacnt bases of $R$ and $M$ at the level of the $\mathrm{m}$-cu crossvein, which is the more usual location of the basal piece of MA in most other Neuroptera.

I feel, however, that this more proximal crossvein is a secondary development in those genera where it is present and that the true basal piece of MA is really the more distal vein. My principal reason for this conclusion is that I am unable to find a second, more-proximal vein in the fore wings of such generalized berothids as Cyrenoberotha and Rhachiberotha, where the bases of $R$ and $M$ are rather widely separated and where such a vein, if present, should be easily seen. Again, in the even more generalized berothid relatives of the Neurorthidae and Dilaridae, where the relationships of the veins at the base of the fore wing are equally well made out, only a single vein is present between these longitudinal veins, which in the nallachiine
} 
one can, I feel, maintain strong reservations about the importance of this set of alternatives as a taxonomic character. The degree of development of the basal piece of MA is subject to a good deal of variation, largely because of the weakening of its sclerotization which results from the line of flexion passing through it. This difficulty in detecting the vein is compounded when the vein is located in a relatively more proximal position between the approaching bases of $\mathrm{R}$ and M.. As a result of these considerations, I believe that it would be premature to assume that Costachillea cannot be closely related (or perhaps congeneric) with Sphaeroberotha until, at a minimum, specimens of Costachillea have been examined to see if perhaps a poorly sclerotized basal piece of MA is not present after all which was missed by Navás.

The final genus of berothines with rounded wing apices which should be considered is Cycloberotha. The characters which have seemed to separate this genus from Sphaeroberotha are the number of radial crossveins, the number of branches of the radial sector, and the presence or absence of squamae on the females. With respect to the number of radial crossveins, Navás (1929, 1930) has stated that Cycloberotha is characterized by the possession of three. Although this is true for the type species, $C$. mjobergi (Esben-Petersen), Navás has erred in evaluating this feature in the second species of this genus, C. neuropunctata (Esben-Petersen), where only two radial crossveins are present. Esben-Petersen (19I7) states this quite clearly in his original description of this species and I have verified this fact from the examination of a series of specimens of this species in my collection. The number of radial crossveins is frequently rather constant within groups of closely allied species and it may be that $C$. neuropunctata has been incorrectly assigned to Cycloberotha. Precedent, however, exists in both Berotha and in the rather well-studied Lomamyia for including in the same genus species with differing numbers of radial crossveins so that $C$. neuropunctata should not be excluded from Cycloberotha on the basis of this feature alone. In any

Dilaridae is relatively distal in position and is slightly sinuate as it is in the fore wings of many berothids. Unfortunately, comparisons with the closest relatives of the Berothidae, the Mantispidae, cannot be drawn, since even in the most generalized of the Platymantispinae, the bases of $R$ and $M$ of the fore wing are too closely adjacent to permit study.

${ }^{4}$ In evaluating Navás' descriptions an additional, essentially semantic problem is added to these sources of confusion: a vein is only an "internal radial vein" if it is located proximal to the fork of MP. Where the vein is located distal to this fork it no longer qualifies as an "internal radial vein" and the taxon is described as lacking the vein (cf. Navás, 1929, p. 23). 
case, attempts to separate Sphaeroberotha and Cycloberotha on the strength of this single character is made impossible by the present heterogeneous composition of Cycloberotha.

The number of branches of the radial sector is likewise unsuitable as a criterion for distinguishing these two genera, since $C$. neuropunctata and $S$. dumonti both have an identical pattern of branching of the radial sector. It is true that the type specimen of $C$. mjobergi has one fewer branch in the radial sector of the fore wing, but as has been recently noted (MacLeod and Adams, I967) slight differences in the number of branches of the radial sector are probably too variable a feature to use as a taxonomic character of generic distinction. The presence of squamae on the females of Cycloberotha is likewise an insufficient reason for separating these two genera, since otherwise closely related species are known in both Berotha and Lomamyia which differ in the presence or absence of these squamae on their females.

With the present state of our knowledge concerning the genera presumed to be somewhat related to Sphaeroberotha, it is not possible to more than guess at what the diagnostic features of the genus might be, assuming that it is actually a valid entity. Certainly none of the taxonomic characters discussed above is sufficiently free from suspicion to serve as a guide in this direction. As a tentative guess, since I have not observed them in the form seen in Sphaeroberotha elsewhere in the family, I might suggest that the sclerotized, "snail-shell" specialization of the proximal portion of the copulatory bursa and the presumptive glandular elements associated with the distal portion of the spermatheca (rather than in their more usual position along the fertilization canal) may perhaps prove of diagnostic importance. There is a similar sclerotization of this portion of the copulatory bursa in Cyrenoberotha of the distantly related Cyrenoberothinae, although here the sclerotized portion is not coiled and of course there are many other differences. Again, in the somewhat more closely related Naizema (but not in Trichoberotha), there is a tendency for a weak sclerotization of this portion of the copulatory bursa (MacLeod and Adams, r 967). Here again, however, there is no tendency for a coiling of this sclerotized portion. Finally, Trichoberotha (to be redescribed in a subsequent paper of this series) has a superficially similar, snail-like coil in the sperm-conducting pathway; however, here it is the spermatheca itself, rather than a portion of the copulatory bursa, which shows the apparent similarity. There are, in addition, 
many other important differences between Sphaeroberotha and Trichoberotha.

The foregoing analysis, which I regret has been unable to settle any question as to the position or validity of Sphaeroberotha, emphasizes the great need for a better understanding of the detailed structure of a large segment of the species and genera of the Berothinae. ${ }^{5}$ Future descriptive work must carefully re-evaluate the effectiveness of the taxonomic characters which have been used in the past and must make available the condition of characters whose importance has usually not been properly appreciated up until now. In particular, I feel that among the more important features for the characterization of valid genera are the structure of the male and female genitalia and of the internal, sperm-conducting and storage system of the female. Such details of the male as the degree of development of the gonarcus and gonocoxites and the basic form and length of the mediuncus and its terminal setae will probably be of great help in this attempt. In the female, the size and shape of the 7 th and 8th sternites, the degree of development of hypocaudae, the presence or absence of 9 th gonapophyses, and, especially, the structural details of the copulatory bursa and spermatheca should also be carefully evaluated.

KRÜGER, L.

\section{Literature Cited}

1922. Berothidae. Beiträge zu einer Monographie der NeuropterenFamilie der Berothiden. Stett. Ent. Zeit. 83: 49-88.

1923. Neuroptera succinica baltica. Die im baltischen Bernstein eingeschlossenen Neuropteren des westpreussischen ProvinzialMuseums in Danzig. Stett. Ent. Zeit. 84: 62-92.

Esben-Petersen, P.

1917. Australian Neuroptera. Part III. Proc. Linn. Soc. New South Wales 42: 203-219.

Macleod, E. and P. Adams.

1967. A review of the taxonomy and morphology of the Berothidae, with the description of a new subfamily from Chile (Neuroptera). Psyche 74: 237-265.

${ }^{5}$ Through the courtesy of Dr. O. S. Flint, the berothids of the Neuroptera collection of A. Alfieri, recently acquired by the U. S. National Museum, have been loaned to me for study. The collection contains specimens of Nodalla, including the holotype of $N$. aegyptiaca Navás, the type species of this genus. Preliminary study of these specimens reveals the same basic pattern of wing venation and female genitalia as Sphaeroberotha and indicates a probable synonymy of these two taxa. This material will be described in a future paper of this series. 
Navás, L.

1927. Névroptères d'Egypt et de Palestine. $3^{\text {me }}$ partie. Bull. Soc. Roy. Entom. d'Egytpe 1926: 192-216.

1929. Monografía de la familia de los Berotidos. Mem. Acad. Ci. Zaragoza 2: 1-106.

1930. Insectos del Museo de Paris. $6^{\text {a }}$ Serie. Broteria (Ser. Zool.) 26: 120-144. 

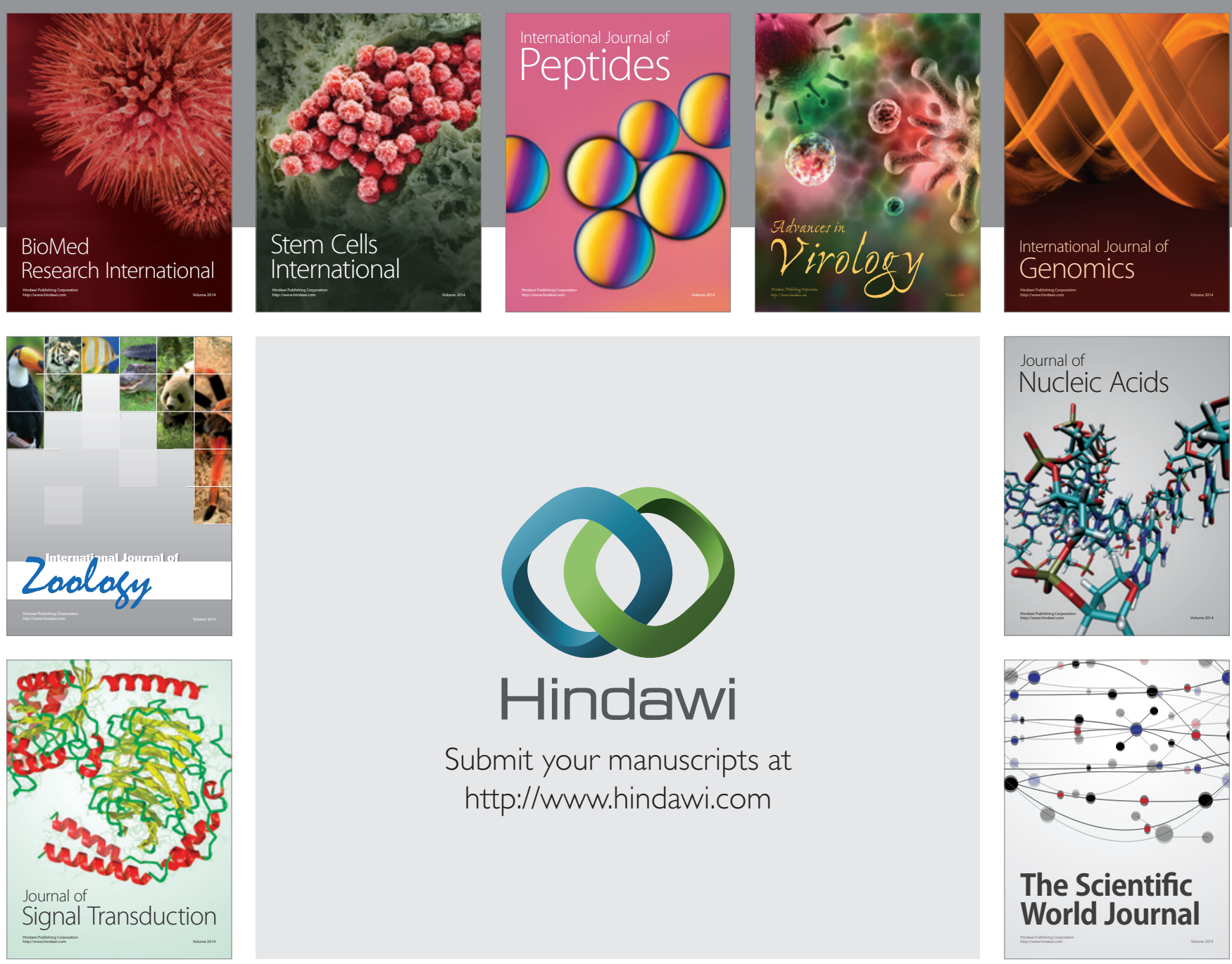

Submit your manuscripts at

http://www.hindawi.com
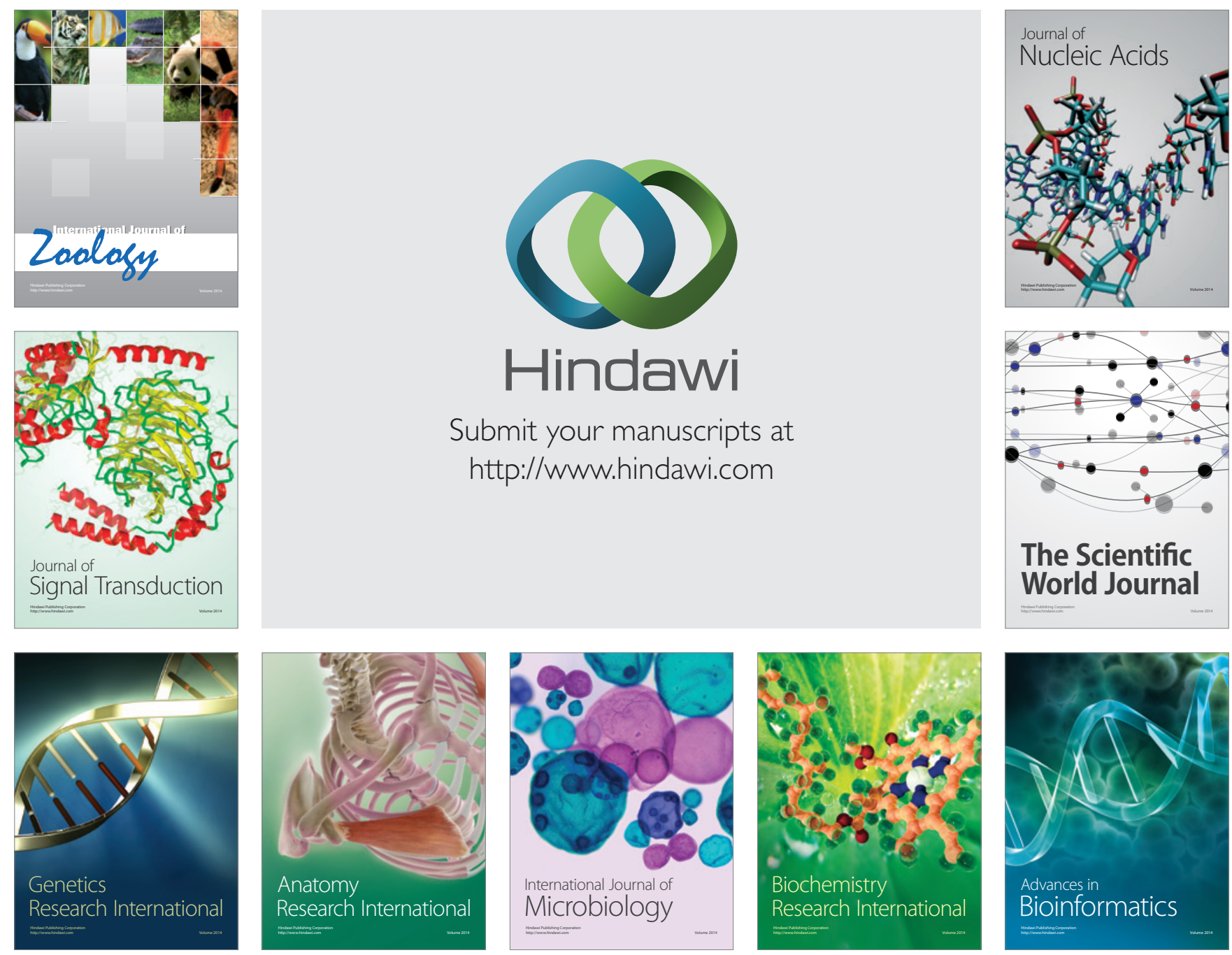

The Scientific World Journal
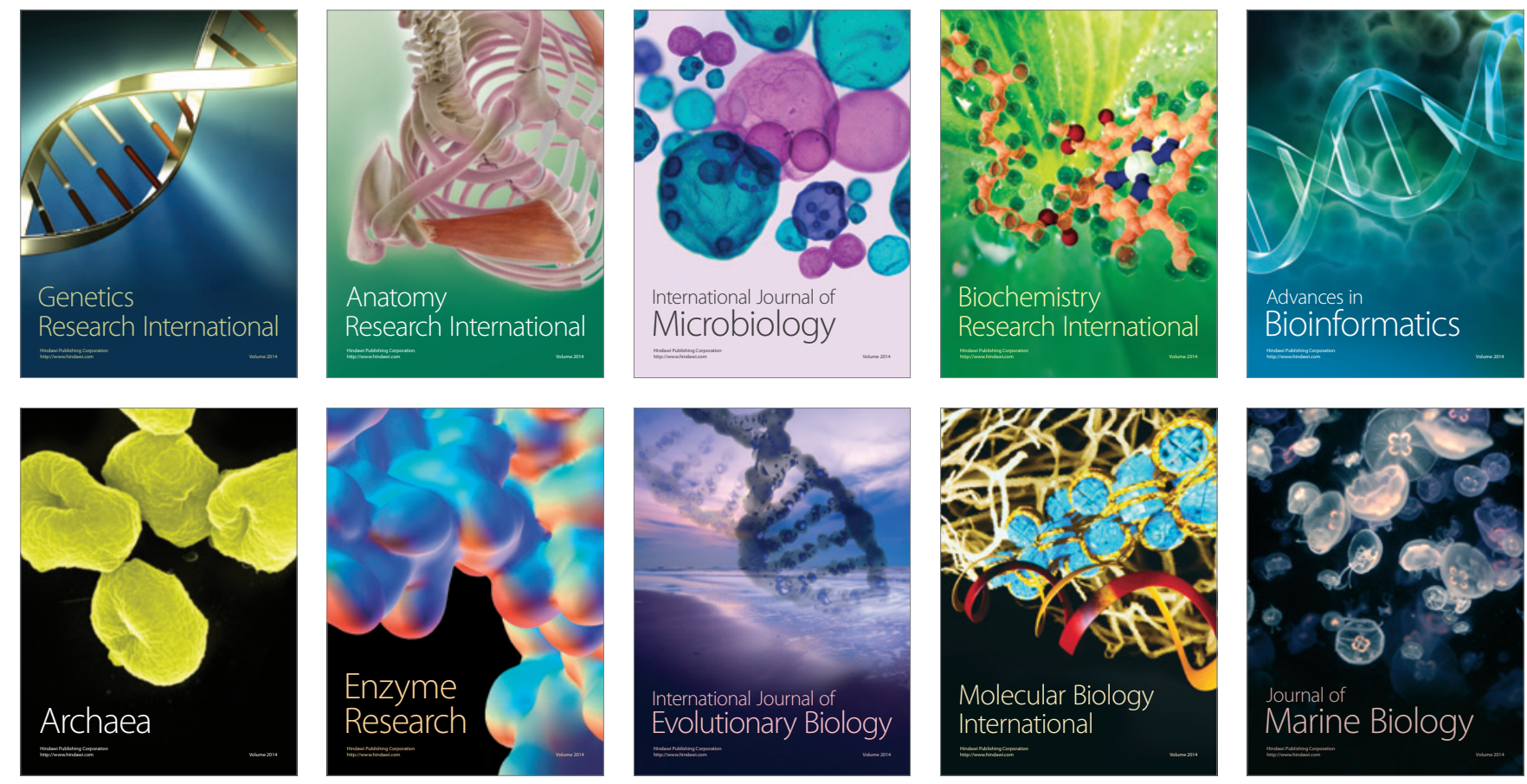